\title{
Dançar, mover, deslocar: o corpo na formação dos profissionais da educação infantil
}

\section{Dancing, moving, displacement: the body in training e arly childhood professionals}

Adrianne Ogêda Guedes é Professora Adjunta da UNIRIO, especialista em Educação Infantil PUC-RJ, com formação na Escola Angel Vianna (RJ) e Arte Educadora com Helio Rodrigues.

Coordenadora do Grupo de Pesquisa Frestas.

Contato: adrianne.ogeda@gmail.com

Lívia Lage é Licenciada em Dança Contemporânea pela Faculdade Angel Vianna (RJ), especializou-se em Educação Infantil pela PUC-RJ e possui formação como Arte Educadora, com Helio Rodrigues, pelo Instituto Pró-Saber (RJ). Formou-se professora da Técnica Alexander, no Alexander Technique Studio, Londres. Pesquisadora do Grupo Frestas.

Contato: lagelivia@gmail.com

Nuelna Vieira é Graduada em Psicomotricidade pelo Instituto Brasileiro de Medicina de Reabilitação, especialista em Educação Infantil pela PUC-RJ e mestrado em Psicologia Social pela Universidade do Estado do Rio de Janeiro (2009). Coordenadora da Casa Monte Alegre, Educação Infantil e pesquisadora do Grupo Frestas.

Contato: nuelnavieira@gmail.com

\section{Resumo}

0 presente trabalho aborda aspectos referentes aos princípios teórico-metodológicos dos cursos de extensão para profissionais da rede pública de Educação Infantil do Rio de Janeiro realizados em 2013 e 2014 na Universidade Federal do Estado do Rio de Janeiro (Unirio) em convênio 
com o Ministério da Educação e Cultura (MEC). O foco central voltou-se para o campo das artes, em especial as artes corporais. Neste artigo nos dedicamos a explorar os efeitos dessas experiências nos participantes, com vistas a reunir subsídios para investigar perspectivas teórico-metodológicas para a formação de professores. Destacamos excertos das entrevistas realizadas com os professores que trabalharam a dimensão corporal nesses cursos, em articulação com estudos do campo da corporeidade e da educação estética. Palavras chave: Educação estética. Artes corporais. Formação de professores.

\section{Abstract}

The present work deals with aspects related to the theoretical-methodological principles of the extension courses for professionals of the Public Network of Early Childhood Education of Rio de Janeiro held in 2013 and 2014 at the Federal University of the State of Rio de Janeiro (Unirio) in agreement with the Ministry of Education and Culture. The central focus was the field of the arts, especially the body arts. In this article we focus on exploring the effects of these experiences on the participants, with the aim of gathering information to investigate the theoretical-methodological perspectives of teacher education. We highlight excerpts from the interviews with the teachers who worked the corporal dimension in these courses, in articulation with studies of the field of corporeity and aesthetic education. Keywords: Aesthetic education. Body Arts. Teacher training.

\section{Introdução}

$$
\text { O grito é um ato corporal puro. }
$$

Leslie Satin

0 que acontece quando o corpo acorda? Para Larrosa (2002, p. 21) "a cada dia se passam muitas coisas, porém, ao mesmo tempo, quase nada nos acontece". Se apuramos o olhar para as situações cotidianas na vida do educador, na sala de aula, podemos ver, ouvir, sentir: olhares, ruídos, gritos, pedidos, exigências, brincadeiras, regras, sentimentos, cansaço, vontades, urgências, fome, infinitos afazeres, ordens, desordens, improvisos, conflitos, afetos... Tudo, diariamente, incansavelmente, repetidamente, compulsoriamente, passa e quase nada acontece. Alunos e 
professores se esbarram, mas parecem não se encontrar, não se afetar com as presenças mútuas. Olhando de perto, nota-se uma circulação desencantada pelos espaços escolares: singularidades aplainadas por uma rotina normativa que esfria as relações com o outro e distancia das percepções de si mesmo. Rotinas mecanizadas. Corpos silenciados. Se estivesse olhando para esse cenário de uma sala de aula, Larrosa descortinaria a paisagem revelando que "tudo o que se passa está organizado para que nada nos aconteça". (2002, p. 21)

Focando em especial o profissional da Educação Infantil evidencia-se seu desafio permanente: o estabelecimento de relações de escuta e diálogo com as crianças pequenas. Relações que, como quer Larrosa (obra citada), se constituam em encontros e acontecimentos. Onde mutuamente crianças e adultos afetemse. 0 desafio relacional requer um compromisso com a infância, sua forma peculiar de compreender o mundo e interagir com pessoas que a cercam. Exige escuta profunda, de modo a distanciar-se de práticas que reforçam as relações de dominação entre adultos e crianças, desrespeitando suas expressões, sentimentos, emoções. 0 caminho de afecções mútuas se faz não somente em direção ao outro como também no aprofundamento do conhecimento de si mesmo, trabalhando os obstáculos que se interpõem aos encontros.

É, portanto, fundamental resgatar a dimensão ética do cuidado e agir com sensibilidade para reconhecer as necessidades de atenção e afeto das crianças pequenas. Guimarães (2011, p. 48) sublinha a importância de tirar o cuidado de uma dimensão instrumental, cuja ênfase recai na disciplinarização e controle sobre os corpos, para colocá-lo na esfera da existencialidade, que supõe uma concepção de educação como encontro da criança com o adulto, num sentido de diálogo, abertura e experiência compartilhada. Desse modo, o cuidado é considerado em sua dimensão ética e compreendido como indissociável do processo educativo seja da criança ou do educador.

De que maneira essa sensibilidade relacional, que supõe escuta profunda do outro e de si mesmo, se constitui? É possível "ensinar sensibilidade"? Essa instigação tem mobilizado nossas pesquisas e estudos referentes ao campo da formação docente na interface com a Educação Estética. Consideramos que a educação da sensibilidade se dá por meio de rotas distintas daquelas que geralmente conduzem o caminho formativo do profissional de Educação Infantil, no âmbito da educação formal - seja em nível médio ou superior -, com forte apelo à aprendizagens conceituais 
genéricas do vasto campo educacional e baixo vínculo com o campo de trabalho docente, nas instituições de Educação Infantil, em interações diretas com as crianças.

Modelo fragmentado entre teorias e práticas, entre idealizações abstracionistas sobre o processo educacional e os acontecimentos que de fato transcorrem nas situações concretas de trabalho, entre o que se pensa, o que se faz, o que se sente. Além da fragmentação do modelo de ensino, há a fragmentação na forma de ensinar e aprender, na qual as apreciações sensório-perceptivas, seja do educador ou do educando, são invisibilizadas, descuidadas, ao longo da preparação para tornar-se docente. 0 exercício do magistério na Educação Infantil não permite ignorar a dimensão sensível tão presente e significativa no processo educacional da criança e nas interações presenciais entre crianças e adultos na instituição educativa. Apresenta-se um abismo entre aquilo que proclamam os discursos sobre a indissociabilidade do educar e cuidar, o protagonismo da criança no processo educacional, a importância das linguagens expressivas no desenvolvimento infantil para a efetivação de propostas pedagógicas que reclamam um redimensionamento do lugar do corpo, da imaginação, das emoções, dos sentimentos, das expressividades no processo educacional.

É por isso que apostamos que o desvio de rotas no processo formativo docente deve fazer-se no sentido de amalgamar esses elementos dispersos e fragmentados por meio de propostas formativas que confiram atenção aos nossos fenômenos estésicos e estéticos (DUARTE Jr, 2006) e comprometam-se com a dimensão corporal e expressiva dos sujeitos, crianças e adultos. A estética é uma concepção de difícil alcance racional justamente pelo fato de extrapolar o âmbito cognoscente mentalista e embrenhar-se pelas vias sensório-perceptivas de acesso ao mundo. 0 acontecer dos acontecimentos demanda o despertar da anestesia à estesia.

Este artigo traz uma experiência de formação de profissionais da Educação Infantil que tomou como desafio nortear-se pelos estudos da Educação Estética. Nos anos de 2013 e 2014 oferecemos na Universidade Federal do Estado do Rio de Janeiro dois cursos de extensão de 90 horas, com duração de um semestre e aulas semanais voltados para profissionais em exercício nas instituições públicas de Educação Infantil do Rio de Janeiro, como parte do convênio firmado entre o Ministério de Educação (MEC) e as instituições federais do país. Intitulados "Arte, Corpo e Natureza" os cursos focalizaram as linguagens artísticas, em especial aquelas voltadas para o corpo. 
Os caminhos teórico-metodológicos dessa proposta de formação buscaram articular estratégias com vistas a oportunizar experiências que se propunham a nos despertar do torpor cotidiano - que passa desapercebido/anestesia - e nos dispor ao acontecimento/estesia - que marca, rompe, desloca. Compreendemos que é preciso que algo aconteça no campo da educação em que o trabalho docente, enquanto atividade de interações humanas (TARDIF e LESSARD, 2007), é central para a mobilização desse despertar. Buscamos então, na formação continuada de professores de Educação Infantil, o espaço/tempo da experiência estética e investigamos as repercussões dessa ação formativa. Experiência é aqui entendida como aquilo que nos passa, nos acontece, nos toca (LARROSA, 2002).

Neste artigo voltamo-nos aos efeitos das experiências corporais vividas pelos participantes dos processos formativos em pauta: como afetaram os professores e suas práticas? Como repercutiram no outro educando e educador? Provocaram acontecimentos? Ampliaram a escuta? Empreendemos aqui um esforço reflexivo que se volta à experiência formativa proposta e vivenciada por nós enquanto formadoras, pesquisadoras, professoras, pois apostamos na necessidade de nos conectarmos àquilo que vivemos, ao que nos aconteceu, articulando seus sentidos e significados para dar continuidade à formação integral e sensível de professores de Educação Infantil. Afirmamos, assim, a sensibilidade como especificidade da função docente nessa etapa educativa.

A investigação relatada nestas páginas teve como objetivo compreender a perspectiva dos professores formadores, cujas aulas lecionadas ao longo dos cursos privilegiaram experiências na linguagem corporal, sobre as repercussões dessas experiências nos professores cursistas. 0 interesse em compreender a ótica desses sujeitos refere-se ao fato de serem leigos em relação à Educação Infantil e, ao mesmo tempo, terem vasta experiência nas linguagens artísticas/corporais que propuseram em suas aulas. Como analisam a repercussão das aulas naqueles sujeitos? Como se deu a interatividade entre esses formadores e os professores de Educação Infantil? O que emergiu de suas trocas?

Para conhecer suas perspectivas optamos por realizar entrevistas após o encerramento do segundo ciclo do curso, no ano de 20141. A partir desses depoimentos é possível compreender os objetivos que nortearam as práticas propostas e de que forma o grupo, e cada um, foi reagindo às proposições, se afetando e descobrindo mais sobre si mesmos.
1. As entrevistas foram gravadas e transcritas, tendo algumas delas gerado pequenos artigos publicados em 2015 no Dossier Formation des instituteurs pour une autre éducation infantile, disponível no site francês Ritimo.ogr (https://www.ritimo.org/Formation-des-instituteurs-pour-une-autre-education-infantile). 
Neste artigo selecionamos trechos dessas entrevistas que remetem às percepções desses professores a respeito de como a experiência foi percebida por eles, como observaram o grupo de professores cursistas e o que intencionavam mobilizar nos sujeitos com suas proposições. Desse modo, trazemos aqui o exercício de investigação dos sentidos emergentes das práticas docentes do curso, por meio do discurso dos professores formadores. Buscamos pistas para refletir sobre a tríade formação, experiência e infância associada na metodologia formativa do curso "Corpo, Arte e Natureza".

\section{Os cursos de extensão: espaços de experiência}

Os cursos assentavam-se em uma concepção de formação que caminhava na contramão de uma perspectiva prescritiva, técnica, instrumental. Assumimos como princípio norteador das atividades formativas propostas planejar encontros que convidassem às experiências, ao despertar do acontecimento. Para isso, optamos por propor atividades corporais que tivessem como estratégia mobilizar ao movimento, atentar à respiração, despertar à percepção de si e do espaço.

Colocamos em tensão a concepção vigente que subsidia algumas propostas formativas que consideram o professor como o sujeito da falta. Aquele a quem bastaria um curso de atualização/formação que o "preenchesse" com um aparato teórico, tornando-o apto a realizar um trabalho supostamente mais qualificado. Tal concepção considera o professor como alguém a ser "submetido" a uma formação, entendendo os conhecimentos docentes como cumulativos, passíveis de serem renovados por um conjunto de tecnologias de cunho preparatório. Na contramão dessas ideias, afirmamos o professor em sua potência autoformadora (AMORIN e CASTANHO, 2008). Seu percurso de vida-formação (JOSSO, 2004) inclui as experiências vividas em seus grupos de referência, com outros educadores e com as crianças. É no diálogo com o outro, que ajuda a ver de uma nova forma e convoca ao deslocamento, que nos formamos. Também inclui as experiências do âmbito pessoal, seu próprio percurso estético que vai impactando a subjetividade do sujeito e constituindo sua forma de ser e estar no mundo.

Apostamos também numa formação que considera a experiência de corpo inteiro em sua potência mobilizadora do sujeito. Ou seja, aquilo que ele pode experimentar, deixando- 
-se penetrar, mobilizando seus sentidos de forma mais ampla, constitui-se num conhecimento encarnado, e não na mera erudição. Nessa perspectiva, a formação de corpo inteiro é aquela que, ao mobilizar integralmente o sujeito, não o parte em dois - razão/emoção, cognição/afeto. Ao romper com os dualismos presentes na modernidade, o conhecimento passa a constituir o sujeito e se faz presente na forma como ele passa a operar no mundo. Seus sentidos, aquilo que afeta seu campo sensorial, aromas, toques, sons, relações, sabores, são percebidos e relacionados com sentimentos, ideias, produzindo sentidos (LE BRETON, 2006). Experiências do campo da sensibilidade, que tocam o ser poético e sensível e conformam o que somos. Abrem escutas e percepções.

Para desenvolver o trabalho nos referidos cursos convidamos professores com um perfil bastante particular. Todos, ou a maioria, eram profissionais que atuavam não apenas como professores, mas também como artistas e/ou terapeutas. Isto é, a experiência criativa estava presente e, à época, alguns deles estavam em cartaz com seus trabalhos (levar os professores cursistas para vêlos fez parte do projeto). Ainda que alguns tivessem experiências com crianças pequenas e escolas, não tinham, em sua maioria, conhecimentos específicos sobre a Educação Infantil. 0 foco ali era claro: aquele era um espaço para que os adultos experimentassem! Interessava-nos a possibilidade de que os participantes pudessem experimentar em si próprios as propostas do curso, sem que tivessem como perspectiva uma possível aplicabilidade direta sobre as crianças.

Os cursos tiveram a duração de um semestre com encontros de quatro horas aos sábados. Em sua estrutura também estavam previstos estudos que tematizavam o campo das artes em diálogo com a Educação Infantil. A ementa consistia em abordar os seguintes temas: 1) Criação e imaginação na infância; 2) Educação estética, infâncias e linguagens artístico-culturais; 3) A arte na Educação Infantil; e 4) Corpo e movimento na formação do profissional da Educação Infantil.

No núcleo de Corpo e movimento - foco deste texto trabalharam conosco seis professores. Alexandre Bhering, professor, filósofo e bailarino formado na Escola e Faculdade de Dança Angel Vianna; Andrea Jabor, bailarina, coreógrafa e diretora da Companhia Arquitetura do Movimento; Enamar Ramos, bailarina, pedagoga e professora da Escola de Teatro da Unirio; Érika Reis, bailarina, fisioterapeuta e especialista em Corpo, Educação e Diferença pela Escola e Faculdade de Dança Angel 
Vianna; Flávia Reis, atriz e palhaça, e Joana Ribeiro, bailarina, professora do Departamento de Interpretação Teatral da Escola de Teatro da Universidade Federal do Estado do Rio de Janeiro/Unirio, com doutorado em Teatro e experiência na área de Artes, com ênfase em coreografia e preparação corporal, dança, performance, ensino e pesquisa. Inicialmente nos reunimos com os professores convidados e apresentamos nossa proposta metodológica, bem como apresentamos um panorama dos desafios referentes a Educação Infantil. Esse diálogo inicial visava municiá-los a planejarem ações consonantes com os objetivos dos cursos.

\title{
O encontro com nosso corpo e a educação estética
}

\author{
Quem experimenta? O corpo. Quem inventa? Ele. (SERES, 1999) \\ O corpo não é, portanto, uma matéria passiva, submetida ao controle da \\ vontade, obstáculo à comunicação, mas, por seus mecanismos próprios, \\ é de imediato uma inteligência do mundo. Esse conhecimento sensível \\ inscreve o corpo na continuidade das intenções do indivíduo confrontado \\ a seu ambiente; ele orienta em princípio seus movimentos ou suas ações \\ sem impor a necessidade preliminar de uma longa reflexão. De fato, na vida \\ cotidiana, os mil movimentos e ações que enriquecem a duração do dia são \\ feitos sem a mediação profunda do cogito - encadeiam-se naturalmente \\ na evidência da relação com o mundo. (LE BRETON, 2003, p.190)
}

Le Breton convoca nosso olhar para as relações corporais que estabelecemos com o mundo. Para o autor, o contexto que vivemos na grande parte das cidades urbanizadas do ocidente, em que a navegação na internet ou a realidade virtual proporcionam o sentimento de estarmos presos a um corpo estorvante e inútil,o qual é preciso alimentar, cuidar, manter..., nos dissocia do nosso corpo, que passa a ser mero suporte para um suposto "eu" que parece estar em outro lugar, "ligado a prazeres corporais toscos, como a comida compulsiva, possam gerar a sensação de que esse eu se encontra no comando (...)" (DUARTE JR., 2010, p. 101).

Duarte Jr (obra citada), ao abordar a concepção de corpo como produto de uma educação que se dá em uma sociedade e em uma cultura determinadas, elucida o entendimento de que é com o corpo que nos instalamos no mundo, sua aparência e mobilidade são apreendidas e desenvolvidas num ambiente social e, portanto, é fundamental pensar na educação básica à que estamos submetidos, além dos efeitos relativos aos meios de comunicação em nossa realidade contemporânea. Defende também, apoiado nos estudos de Le Breton, que nos dias que correm as práticas sociais 
nos incentivam a despender o mínimo possível de energia corporal na execução das ações cotidianas. Essa maneira aparentemente mais confortável de viver o corpo em nossa sociedade é reforçada por subprodutos prejudiciais à saúde humana física e mental, tais como colesterol elevado, depressão etc. Assim, o corpo se vê mais e mais restrito e debilitado, o que implica um raio de ação menor sobre o mundo.

\section{(...) O corpo é uma carga tanto mais penosa de assumir quanto seus usos se atrofiam. Essa restrição de atividades físicas e sensoriais não deixa de ter incidências na existência do indivíduo. Desmantela sua visão de mundo, limita seu campo de iniciativas sobre o real, diminui seu sentimento de constância do eu, debilita seu conhecimento direto das coisas e é um móvel permanente de mal-estar. (LE BRETON, 2003, pp. 20-21)}

Na base do relacionamento contemporâneo com o nosso corpo há que se verificar uma forma de estar no mundo que vem sendo construída desde a modernidade. Em linhas gerais, esse período histórico caracterizou-se pela consolidação da perspectiva científica como forma de conhecimento do mundo. Um conhecimento que substitui os dados obtidos com os sentidos pela mensuração dos fenômenos, sua transformação em quantidades e conceitos abstratos de validade universal. Disso derivou um processo de abstração crescente (SABATO, 1993) em que o corpo como fonte de saber foi sendo deslocado em prol do conhecimento construído quase que exclusivamente pela mente, pela representação abstrata das coisas e de suas relações conceituais e matemáticas. Assim o conhecimento tomado por verdadeiro passou a independer dos sentidos.

Se é inegável reconhecermos os inúmeros ganhos para a humanidade com o advento da ciência, interessa-nos aqui focalizar os efeitos específicos nas relações do homem contemporâneo com seu corpo e sua corporeidade. De fato as mudanças advindas da modernidade produziram uma alteração na forma de vivenciar e utilizar o corpo, a infância, a vida adulta.

Nosso corpo conhece o mundo antes que a mente possa transformá-lo em signos representativos de coisas, situações e relações. 0 saber sensível, proveniente de nossos órgãos dos sentidos, precede o saber inteligível e a ele se integra na produção de significação. 0 saber sensível pelo qual conhecemos o mundo de forma sensório-perceptiva foi chamado pelos gregos de aisthesis (estesia em português), constituindo-se como um saber primordial e corpóreo. É a partir desse saber que os demais são construídos, como as abstrações filosóficas, científicas etc. 
Anestesiados com o convite permanente da modernidade de nos abstrairmos de nossa corporeidade, crianças e adultos veem afetadas suas formas de relação com a vida e mundo onde se encontram.

A educação estética, ou educação do sensível, se ancora na realidade físico-corporal, que elabora e redefine o modo como percebemos nosso corpo em suas ações e trocas com o ambiente no qual vivemos. Educação na qual se cultivam sensações, sentimentos, percepções que possibilitem uma "harmonia corpomundo" (DUARTE JR., 2010, p. 114). Nesse sentido, entende-se ser necessário redimensionar os parâmetros de vida social - aqui com ênfase nas instituições de Educação Infantil - que promovam oportunidades de escuta da sabedoria dos corpos de crianças e adultos, possibilitando que se dê sentido às experiências em diálogo com nossa escuta sensível e corporal do mundo.

Numa sociedade na qual o pensamento cartesiano e religioso impera e se mantém vivo nas inúmeras tentativas de compreender a vida, o humano, torna-se complexo colocar o corpo no centro da sala de aula, da formação do professor; torna-se urgente pensar sobre o que faz de nós essa forma de conhecimento. Que poder é esse que torna arriscado investir no que pode um corpo ${ }^{2}$ (Espinosa, 2007). Mas optamos por começar pela experiência sensível direta, com o corpo.

Corpo, território dos acontecimentos."O que é o corpo? (...) Nada mais do que quantidades de força em relação de tensão umas com as outras" (DELEUZE, 1976, p.32). 0 corpo, dessa forma, é visto como um estado de coisas que se encontra num instante qualquer, único. 0 corpo não é. 0 corpo está sendo. A perspectiva de uma vida no gerúndio abre espaço para o tempo de cada instante, para as relações presentes em cada instante, para o que 0 afeta em diferentes instantes. Assim, o compreendemos como uma resultante de acontecimentos, atravessamentos, afecções que deixam marcas inscritas pelo vivido - e pelo não vivido.

Deleuze diz que para Espinosa um corpo, por menor que seja, sempre comporta uma infinidade de partículas: são as relações de repouso e de movimento, de velocidades e de lentidões entre tais partículas que definem a forma, a individualidade de um corpo. Essas relações, forma e individualidade, são, portanto, constituídas de dinâmicas.

Um corpo afeta outros corpos. Um corpo é afetado por outros corpos.
2. Nos referimos aqui à célebre pergunta de Espinosa: "O que pode um corpo?", presente no seu livro Ética (Espinosa, 2007). 
0 importante é conceber a vida, cada individualidade de vida, uma relação complexa entre velocidades diferenciais, entre abrandamento e aceleração de partículas. É pela velocidade e lentidão que a gente desliza entre as coisas, que a gente se conjuga com a outra coisa: a gente nunca começa, nunca se recomeça tudo novamente, a gente desliza por entre, se introduz ao meio, abraça-se ou se impõe ritmos. (DELEUZE, 2002, p.128)

Nos cursos de extensão "Arte, Corpo e Natureza", colocar o corpo em cena com encontros de danças e propostas de consciência corporal, por exemplo, foi uma tentativa de aproximação com os ritmos, com as possibilidades de deslizamentos, com os afetos, com o que acontece em cada instante, com a possibilidade de criarmos um ponto de partida, buscando a singularidade e as ínfimas diferenças que habitam um grupo de professores. Foi tentar pensar a vida em sua complexidade.

Fomos deslocados pelas alterações corporais perceptíveis que acontecem nos encontros que nos modificam. Há uma alteração corporal quando um indivíduo encontra um ritmo próprio. As aulas convidavam à percepção de si mesmos por meio de danças populares, jogos e folguedos, ampliando o repertório vivencial na linguagem da dança daqueles em formação, encorajando-os para que descobrissem suas próprias danças. A autoria é aspecto que se destaca quando a coragem de experimentar é maior que o medo de errar, ou quando o risco do novo desconstrói a certeza do já conhecido.

A dinâmica das aulas envolvia, além das propostas vivenciais do campo das linguagens corporais, um tempo precioso dedicado a refletir coletivamente sobre as experiências transcorridas. Nesse momento de trocas foi possível articular as sensações, descobertas, dificuldades, resistências, com as questões relativas aos desafios cotidianos vividos nos espaços institucionais de Educação Infantil. Afinal, a Educação Infantil é necessariamente uma modalidade presencial, para crianças e docentes. Dar visibilidade à dimensão corporal no processo formativo corresponde a assumir a inteireza desse sujeito cuja profissionalidade demanda um corpo presente, vivo, desperto, sensível a afetar-se pelas lógicas peculiares do outro criança.

Com o intuito de aprofundar e dar continuidade à partilha das experiências vividas no âmbito da formação que acontecia aos sábados mantivemos uma página do grupo de professores na rede social Facebook, permitindo ressoar ao longo da semana os ecos do que havíamos vivido coletivamente no espaço formativo. 


\title{
Dois para lá, dois para cá: encontro entre professores da dança e professores da Infância
}

\author{
Todos eles traziam sacolas, que pareciam muito pesadas. Amarraram bem \\ seus cavalos e um deles adiantou-se em direção a uma rocha e gritou: \\ "Abre-te, cérebro!
}

Arnaldo Antunes

Procuramos compreender a experiência de lecionar aulas de linguagem corporal para professores de Educação Infantil: o que narram os professores de linguagens corporais sobre o que lhes aconteceu enquanto formadores nesse curso?

Optamos por entrevistar três professores do campo das artes/ linguagens corporais que compuseram o corpo docente do curso de formação em questão. São eles: Érika Reis; Joana Ribeiro e Flávia Reis, já apresentados anteriormente. As entrevistas permitiram destacar as concepções de trabalho corporal que sustentaram as propostas das aulas, bem como identificar o que, com as experiências vividas, foi mobilizado nos professores cursistas e quais descobertas o curso lhes propiciou. Destacamos abaixo trechos das entrevistas realizadas.

Nas palavras da fisioterapeuta, psicomotricista e terapeuta corporal Érika Reis:

\footnotetext{
A criança é puro movimento!

Daí vem a importância do professor trabalhar seu corpo, descobrindo suas articulações, sua flexibilidade para experimentar no desequilíbrio novos pontos de apoio e novas possibilidades de contato e relação. Assim um corpo disponível para o novo acontecer começa a aparecer... Explorar o pé com bolinhas, caminhar pelo espaço, perceber as travas, as articulações e as possibilidades de movimentação corporal gera no professor sensações, imagens, palavras. Escutem o depoimento de uma aluna-professora após massagear o pé com bolinha:"O pé parece maior, toca o chão, sinto meu pé tocando o chão".

Pé no chão altera todo o eixo corporal. A respiração muda, com o diafragma mais expandido, a percepção de si altera, propicia outras formas de ver, sentir e se relacionar com a exterioridade. A fala ganha corpo. Falamos sentindo, com sentidos! Contagia, emociona e cria um ambiente outro, com relação e contato.
} 
Foto 1: Aula de consciência corporal

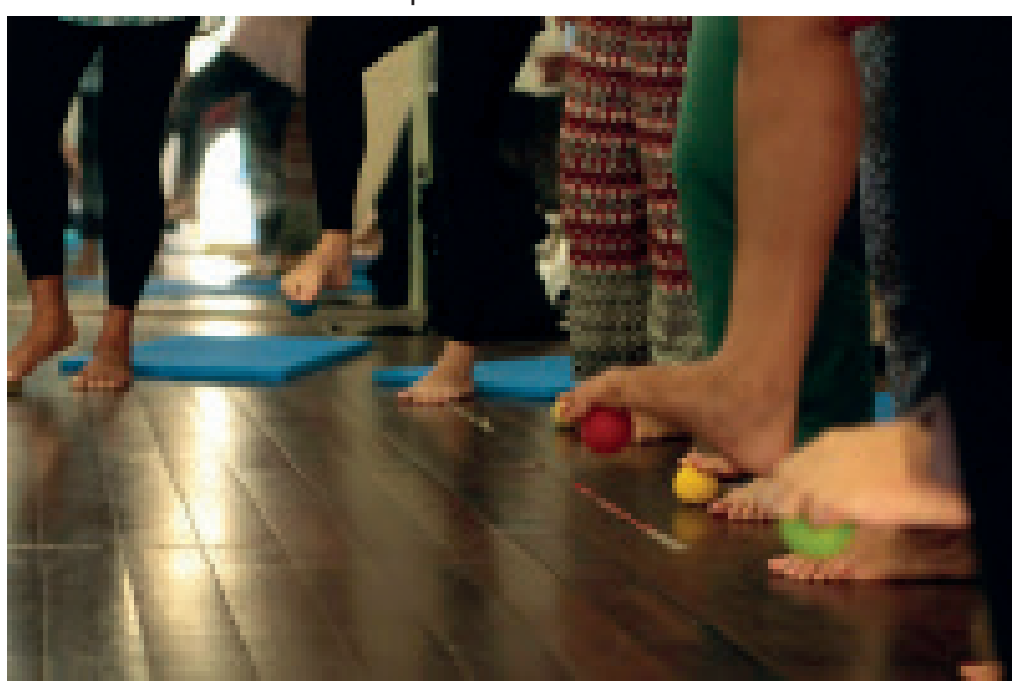

Fico muito agradecida de ter podido trocar com tantos professores que fizeram reflexões incríveis. Exponho aqui a reflexão de uma alunaprofessora que muito me emocionou:

"Todo módulo de corpo me levou a refletir sobre a importância do conhecimento do corpo. 0 aprisionamento dos corpos na Educação Infantil é algo que me inquieta bastante, pois, ao invés de dar espaço para o corpo ampliar, expandir e experimentar, é feito ao contrário, colocar em forma imóvel, inerte.

Pude observar o quão difícil é lidar com seu corpo, tocar o colega, mostrar em público suas fragilidades e fraquezas. Perceber este corpo desde o início da existência e dar suporte para que possa se ampliar, crescer saudável... o módulo de corpo me emocionou em todos os sentidos!" (Professora participante).

\section{A seguir, o relato da bailarina professora Joana Ribeiro:}

(...) Outro elemento significativo desenvolvido nesse trabalho foi o sentido háptico (do grego haptein - tocar), relativo ao sentido do tato. Este sentido diz respeito à capacidade do corpo de transferir sua experiência perceptiva até a extremidade de uma ferramenta, neste caso, a colher de pau. Godard (2010) observa como o sentido háptico é uma das chaves de entrada para a renovação de nossos movimentos. Ministramos em seguida um exercício em duplas, em que uma pessoa exercia uma estimulação na base do crânio e no osso do sacro do parceiro, simultaneamente, através do toque. Após uma fase de experimentação sensorial, a pessoa que recebia o toque passava a ser ativa: a se movimentar vagarosamente, sempre com o outro, tocando-o no crânio e no sacro. Assim, este aquecimento a dois possibilitou uma abertura para o contato com o outro, deixando uma marca em nossa propriocepção e em nosso corpo.

Alguns participantes nos relataram as dificuldades encontradas diariamente no ambiente do trabalho, repleto de estresse, tensões e dores. Muitos 
relataram que se sentiram descansados e dinamizados pelas oficinas de dança. Discutimos a respeito do lugar que esse tipo de oficina poderia ocupar e das transformações que poderia promover no local de trabalho. Outra revelação foi a ressignificação de objetos como estímulo para a criação em dança, despertada pela experiência com as colheres de pau, escovas e cangas.

Foi possível, assim, perceber como a dança sensibilizou o grupo para a necessidade do cuidado de si, o que se afigurou como elemento primordial no cuidado do outro.

\section{Por fim, o trecho da narração da atriz e palhaça Flávia Reis:}

Estávamos em sala de aula lidando com os afetos, e perceber que isso é possível foi muito bonito, muito forte, muito potente. Eu tenho uma experiência com os médicos, enfermeiros e com professores, e percebo que falamos das mesmas coisas: da dificuldade de olhar o outro, da dificuldade de tocar o corpo do outro, de ser tocado, e isso é muito concreto. Quando não consigo me relacionar, parece que fica uma "caixa preta vazia" e não há mais a oportunidade de criação, de se expandir, de estar junto com o outro. Mas é preciso acreditar que algo novo está para acontecer a partir daquela relação, do que sentimos naquele momento. E isso é outro princípio do trabalho do palhaço: eu não tenho expectativas sobre o que vou construir com o outro, eu tenho uma direção apenas.

No trabalho realizado com as professoras do curso de extensão "Educação Infantil: Corpo, Arte, Natureza" da Unirio apostei na ideia de que os conceitos que acompanham os gestos do palhaço - quando ele se deixa acontecer no encontro com a criança - seriam os mesmos que acompanham o professor numa relação com a criança, que vai além do simples ensino-aprendizagem, é uma relação de encontro. Inspirada na obra de Arnaldo Antunes (1992) especialmente no livro As Coisas, no qual ele escreve poesias sobre a forma da criança entender o mundo, quando elas dão nome às coisas e as coisas têm os nomes que têm -, trabalhei com as professoras do curso na Unirio questionando de que maneira o professor e a criança compartilham uma mesma forma de entender o mundo, de olhar para as coisas. Acreditava que isso poderia colaborar para despertar o potencial criativo do professor: olhar como uma criança. Quando Arnaldo Antunes escreve esse livro de poesia, ele trata desse lugar criativo da palavra e nos coloca no lugar de quem recria o mundo, questionando-nos sobre o que é a linguagem. Daí surgiu a ideia de trazer para os encontros os processos de criação de espetáculos, como palhaça: escutar os sons, ouvir as palavras como se fosse a primeira vez, entender seus significados. Busquei compartilhar com os professores meu lugar de criação, o lugar da experiência sensível, pois acredito que tudo o que passa pela experiência sensível nos torna criativos, pouco óbvios. 
0 pé que apoia o chão; a mão que transita do crânio à base da coluna; o gesto que desarticula o significado duro da palavra: ações que desnaturalizam o uso funcional que se faz cotidianamente do corpo, do toque da linguagem. 0 corpo, então, assume outro lugar, ocupa o pensamento de suas sensações e revela-se como "ponto cego" do conhecimento, universo desconhecido cuja aproximação promove espantos. Nas falas dos formadores fica evidente a repercussão, nos professores cursistas, do despertar da própria dimensão corporal propiciado pelas dinâmicas propostas. As aulas revelaram-se como tempos e espaços de acontecimentos, de ruptura com a experiência cotidiana normatizada, que anestesia os sentidos e automatizada as ações "para que nada nos aconteça" (Larrosa, 2002). Assim, repercutiram na qualidade da presença desses sujeitos, na ampliação da escuta sensível, na maneira de perceber o outro e a si mesmos. Como perceber a dimensão corporal infantil, a integralidade da criança, sem que seja cultivada, igualmente, a integralidade do sujeito docente?

0 trabalho corporal como prática formativa convoca o adulto a uma infância do corpo, em que a experimentação da linguagem corporal sem fins específicos, a sensorialidade, a brincadeira com o movimento, o ritmo, o equilíbrio estão necessariamente implicados, renovam e refrescam a presença viva e dinâmica no tempo presente. A infância, nesse caso, não é apenas um momento do ciclo da vida humana, mas uma disposição.

Reconhecer-se corpo e apostar intencionalmente em desenvolver essa inevitável presença ao longo do processo formativo é implicar o sujeito docente na aprendizagem sensível da ideia de educar e cuidar indissociavelmente; é conhecer sensório-perceptivamente essa concepção muitas vezes assumida apenas de forma retórica; é assumir um processo formativo que atua nas dimensões pessoais e profissionais (NÓVOA, 2013).

Nesses trechos, os professores-artistas convidados apontam efeitos possíveis de quando experimentamos a dança, as técnicas de consciência corporal, o toque, as relações entre sentir, pensar e fazer na formação de professores de Educação Infantil. 0 que nos acontece quando conhecemos mais profundamente o próprio corpo, seus limites, possibilidades, sensações, movimentos, sons, respiros, necessidades? Essas experiências afetam, transformam, encorajam ao reconhecimento da potência da ação subjetiva no coletivo. 0 passo seguinte será investigar, no caso específico dos professores que atuam na Educação Infantil, como essas experiências sensíveis se refletem no cotidiano das instituições onde trabalham, mas esse tópico não cabe ao alcance do recorte do investimento investigativo aqui relatado. 
Ficou explícito nas conversas que mantivemos nos diversos momentos dos cursos, nos pedidos, nos relatos da semana, no compartilhar das fotos e fatos compartilhados entre o grupo na rede social, que os encontros sensíveis os tocavam, deslocando e movendo em novas direções e experiências, afetando também outros encontros, repercutindo em outras interações que íamos estabelecendo.

Há diferenças no antes e depois de experiências que efetivamente nos afetam. Novas questões se abrem nesses movimentos de acordar o corpo e estar mais disponível às percepções sensoriais.

\section{Considerações finais}

0 desafio de produção de conhecimento a partir da experiência é grande, tendo em vista que cada encontro vivido com professores envolveu um sem-número de sensações, emoções, sentimentos, deslumbres, assombros, como diz Kramer (2009). A experiência vivida por cada participante do curso escapa a uma análise meramente quantificável e não se destina a isso. Precisa ser percebida nas frestas. Nos olhares, conversas espraiadas em momentos diversos. A afirmação de que, sim, a promoção de oficinas/experiências com dança/artes/música/consciência corporal teve potencial estético só pode ser feita porque rastreávamos os afetos, as ideias, as imagens, os deslocamentos que a experiência proporcionou. Corpos que se descobriam, sensações gerando percepções de si, do outro, de expansão, de experimentação e criação. Estávamos lá, testemunhamos as expressões vividas, ouvimos a respiração de alívio a cada momento de relaxamento, ouvimos as conversas soltas em meio às oficinas: "Esse é o momento da semana em que me conecto comigo mesma", dizia uma professora após um longo suspiro.

Os corpos nos revelavam - entre respirações que se alteravam, danças que se soltavam dos padrões nas rodas de jongo, cacuriá, nos alongamentos, nos cuidados entre as pessoas, na disponibilidade para escutar o outro, no vivido - que a experiência deixava marcas e produzia sentidos para cada um em diferentes lugares. Um vivido que não termina ali, quando a experiência tem fim. Ele passava a compor uma pessoa, um professor que por onde andava carregava consigo suas imagens, ideias, possibilidades, recursos para estar na vida. 


\begin{abstract}
(...) o que mais aprendemos na conferência do professor Challenger é justamente a impossibilidade de distinguir forma e conteúdo, expressão e matéria. Impossível separar o que o professor diz do que ele faz. Tampouco dá pra distinguir claramente qualquer uma dessas duas coisas daquilo que ele é ou, melhor, daquilo que ele devém. Tem mais: o que ele faz ou o que acontece com ele ou aquilo que ele se torna não é simplesmente uma ilustração, uma representação ou um exemplo do que ele diz. 0 que ele diz é o que acontece com ele. (Ao mesmo tempo, o que acontece com ele também desdiz o que ele diz.) Confundem-se irremediavelmente personagem e conceito, autor e personagem, enunciado e enunciação. Um performático esse professor Challenger. (TADEU, 2002, p.51)
\end{abstract}

Ao longo do curso fomos buscando esse encontro entre o que acontece com o aluno-professor e o que ele diz. Fomos atrás dessa proximidade consigo mesmo, desmontando certezas, padrões e abrindo um campo de possibilidade que afirma um empoderamento de si - uma fala referenciada na própria vivência, no singular, sem generalizações.

Em uma sala de aula, o que acontece? 0 que se passa com aqueles que fazem da sala um acontecimento? Como podemos pensar/saber as inferências entre o que se vive, sendo singular, com as relações do grupo, o coletivo em uma experiência?

Essas entre tantas outras expressões expuseram um mundo infinitesimal vivido por cada um. Esses registros expõem um percurso, guardam em si um pouco dos rastros de cada um. Ao mesmo tempo, eles se transformam nas trocas, nos afetos que produzem em quem esbarra com eles. Mas isso não está dado por si. Esse modo de pensar a vida, de viver a vida, disponível aos afetos e seus efeitos, é uma escolha metodológica. É um modo de compreender o acontecimento, o cotidiano com suas repetições e as formações como um processo de fazer sentir, ampliar as perspectivas.

Ao final do curso os coordenadores e formadores se colocaram a registrar essa vivência, esticando-a e fazendo-a expandir entre outros meios e pessoas. Os relatos de onde extraímos os trechos dos professores aqui citados estão disponíveis na íntegra no dossiê a que nos referimos anteriormente.

Os alunos-professores da primeira turma de 2013 também produziram textos e alguns nos procuraram após o término do curso propondo a continuidade do diálogo com a universidade e dando origem ao grupo de pesquisa ao qual pertencemos. Interessavam-se em estudar melhor os efeitos daquele curso 
de extensão em suas vidas, nas suas práticas e outros temas que a experiência deflagrou. Outros alunos seguiram buscando outros cursos de especialização e/ou mestrados e não é incomum encontrá-los nas atividades culturais oferecidas na cidade, em espaços como museus etc.

Havia um movimento de busca significativamente presente. A experiência proporcionou o acesso a uma diversidade de técnicas corporais que dialogam com as práticas profissionais; a possibilidade de escutar e expressar favorece atitudes que criam laços, compromissos, histórias e a sensação de cuidado que emergia nas variadas vivências; a percepção das diferenças de cada aluno-professor sob a mesma vivência expandia as ideias, as conexões, as reflexões de cada um e do grupo; enfim, toda essa rede de acontecimentos afirmava deslocamentos, alteridades, e a complexidade que há em ser professor, em assumir um grupo e tecer diariamente encontros e possibilidades, pensamentos e rupturas.

\section{REFERÊNCIAS BIBLIOGRÁFICAS}

AMORIM, V.M.; CASTANHO, M.E. Por uma educação estética na formação universitária de docentes. Educ. Soc., Campinas, vol. 29, n. 105, p. 1167-1184, set./dez. 2008

ANTUNES, A. As coisas: 8. ed. São Paulo: Ed. Iluminuras, 2002. (Primeira edição: 1992)

DELEUZE, G. Espinosa: filosofia prática. São Paulo : Escuta, 2002.

DUARTE JR., J.F. O sentido dos sentidos: a educação (do) sensível. Curitiba, PR: Criar edições, 2001.

DUARTE JR., J.F. A montanha e o vídeo-game: escritos sobre a educação. São Paulo: Papirus, 2010.

ESPINOSA, B. Ética. Belo Horizonte: Editora Autêntica, 2009.

Edição original: 2009. 
FERREIRA, L; PRADO, G.; ARAGÃO, A.M. A formação do professor por suas narrativas: desafios da docência. Revista Hipótese, Itapetininga, v. 1, n. 4, pp. 204-227, 2015.

GALLINA, S.F.S. Deleuze e Hume: experimentação e pensar, p. 129/130 in Philósophos 12 (1): 123-144, jan./jun. 2007.

GUIMARÃES, D. Relações entre adultos e bebês na creche: o cuidado como ética. São Paulo: Cortez, 2011.

JOSSO, M.C.. Experiências de vida e formação. São Paulo: Cortez, 2004.

KRAMER, S. (Org.). Retratos de um desafio: crianças e adultos na educação infantil. São Paulo: Ática, 2009.

LARROSA, J. Notas sobre a experiência e o saber da experiência. Revista Brasileira de Educação. Campinas, n. 19, p.20-28, jan/fev/mar/abr 2002.

LE BRETON, D. Adeus ao corpo. Campinas: Papirus, 2003.

LE BRETON, D.. Antropologia dos sentidos. Petrópolis, RJ: Vozes, 2016

OLIVEIRA, I.B. Prefácio in PASSOS, M.C.P. e PEREIRA, R.M.R. (Orgss.). Educação experiência estética. Rio de Janeiro: NAU, 2011.

RICHTER, S. Docência e formação cultural. In: Ser docente na educação infantil: entre o ensinar e o aprender. Ministério da Educação, Secretaria da Educação Básica. MEC/SEB, 2016.

ROCHA, J.C.C. Revista Gesto número 2, junho de 2003.

SABATO, E. Estudos de filosofia da cultura. São Paulo: Loyola, 1993.

SANTOS, N.; TIRIBA, L. (Orgs.) Dossiê Formation de instituteurs pous une autre education infantile. Disponível em https:// www.ritimo.org/Formation-des-instituteurs-pour-uneautre-education-infantile. Acesso em: 30 de nov. 2017. 
SATIN, L.A. performance e o verbo. In: Revista Gesto, dez. 2002, p.16-19.

SERRES, M. Variations sur le corps. Paris: Le Pommier, 1999.

SHUSTERMAN, R. Vivendo a arte. São Paulo: Editora 34, 1998.

TADEU, T. A arte do encontro e da composição:

Spinoza+Currículo+Deleuze. Revista Educação e Realidade, jul./dez. 2002.

TARDIF, M.; LESSARD, C. O trabalho docente: Elementos para uma teoria da docência como profissão de interações humanas. Tradução de João Batista Kreuch. Petrópolis, Rio de Janeiro: Editora Vozes, 2014.

Recebido: 09/03/2018

Revisto: 30/04/2018

Aceito: 09/05/2018 